\title{
Comparison of Field, Greenhouse, and Detached-Leaf Evaluations of Soybean Germplasm for Resistance to Phakopsora pachyrhizi
}

\author{
M. Twizeyimana, International Institute of Tropical Agriculture (IITA), PMB 5320, Ibadan, Nigeria and Department \\ of Crop Protection and Environmental Biology, University of Ibadan, Ibadan, Nigeria; P. S. Ojiambo, IITA, Ibadan; \\ T. Ikotun, Department of Crop Protection and Environmental Biology, University of Ibadan; C. Paul, Crop Sciences \\ Department, University of Illinois, Urbana, 61801; G. L. Hartman, National Soybean Research Center, Urbana, IL \\ 61801; and R. Bandyopadhyay, IITA, Ibadan
}

\begin{abstract}
Twizeyimana, M., Ojiambo, P. S., Ikotun, T., Paul, C., Hartman, G. L., and Bandyopadhyay, R. 2007. Comparison of field, greenhouse, and detached-leaf evaluations of soybean germplasm for resistance to Phakopsora pachyrhizi. Plant Dis. 91:1161-1169.

Fourteen soybean accessions and breeding lines were evaluated for resistance to soybean rust caused by the fungus Phakopsora pachyrhizi. Evaluations were conducted in replicated experiments in growth chambers using detached leaves and under greenhouse and field conditions. In growth-chamber experiments, inoculation of detached leaves with $1 \times 10^{6}$ spores $/ \mathrm{ml} \mathrm{resulted} \mathrm{in} \mathrm{a}$ significantly $(P<0.0001)$ higher total number of pustules and spores per unit leaf area than inoculations with lower spore concentrations. Amending agar medium with plant hormones significantly $(P<0.0001)$ aided retention of green leaf color in detached leaves. Leaf pieces on a medium containing kinetin at $10 \mathrm{mg} /$ liter had $5 \%$ chlorosis at 18 days after plating compared with leaf pieces on media amended with all other plant hormones, which had higher levels of chlorosis. Leaf age significantly affected number of pustules $(P=0.0146)$ and number of spores per pustule $(P=0.0088)$, and 3- to 4 -week-old leaves had a higher number of pustules and number of spores per pustule compared with leaves that were either 1 to 2 or 5 to 6 weeks old. In detached-leaf and greenhouse screening, plants were evaluated for days to lesion appearance, days to pustule formation, days to pustule eruption, lesion number, lesion diameter, lesion type, number of pustules, and spores per pustule in $1-\mathrm{cm}^{2}$ leaf area. Plants also were evaluated for diseased leaf area (in greenhouse and field screening) and sporulation (in field screening) at growth stage R6. There were significant $(P<0.0001)$ differences among genotypes in their response to $P$. pachyrhizi infection in the detached-leaf, greenhouse, and field evaluations. Accessions PI 594538A, PI 417089A, and UG-5 had very low levels of disease compared with the susceptible checks and all other genotypes. Detached-leaf, greenhouse, and field results were comparable, and there were significant correlations between detached-leaf and greenhouse (absolute $r=0.79 ; P<0.0001$ ) and between detached-leaf and field resistance (absolute $r=0.83 ; P$ $<0.0001)$ across genotypes. The overall results show the utility of detached-leaf assay for screening soybean for rust resistance.
\end{abstract}

Additional keywords: disease resistance

During the past decade, soybean rust, caused by Phakopsora pachyrhizi, has gradually spread from Asia to Africa $(19,21)$, South America (34), and, most recently, to the continental United States (25). Soybean rust is now endemic in $\mathrm{Ni}$ geria, after it was first reported in 1999 (1). The widespread distribution and potential for severe yield losses makes soybean rust one of the most serious foliar diseases of soybean worldwide. Severely infected plants show premature defoliation and

Corresponding author: R. Bandyopadhyay

E-mail: r.bandyopadhyay@ cgiar.org

Accepted for publication 6 April 2007.

doi:10.1094/PDIS-91-9-1161

This article is in the public domain and not copyrightable. It may be freely reprinted with customary crediting of the source. The American Phytopathological Society, 2007. reduced green leaf area that correlates negatively with yield components $(16,17)$. Yield losses ranging between 20 and $60 \%$ have been reported in Africa $(10,19)$, while losses of up to $75 \%$ have been observed in Brazil when no control measures are implemented (34).

Current strategies available for the control of soybean rust are the use of fungicides and resistant cultivars. The use of foliar fungicides to manage the disease in commercial plantings adds significantly to production costs (21) and is not a viable option in subsistence soybean production systems in most developing countries. Planting resistant cultivars still remains the most economical way to manage soybean rust. Specific resistance to $P$. pachyrhizi is known, and four single dominant genes have been identified as $R p p_{1}, R p p_{2}, R p p_{3}$, and $R_{p p}$ (14). These four genes condition resistance to a limited set of rust isolates. Soybean leaves express three types of reac- tions depending on specific pathogen isolate and host resistance interactions. When inoculated with some isolates, plants with an immune reaction do not produce any visible symptoms. Other resistant plants produce red-brown (RB) lesions with either no uredinia or only sparsely sporulating uredinia. In contrast, genotypes expressing the susceptible TAN reaction have characteristic tan-colored lesions with many uredinia and abundant sporulation (5).

The quest for breeding commercial cultivars with desirable agronomic traits and durable resistance continues for the highly variable population of the rust pathogen (5) present in many soybean-growing countries $(14,21)$. Germplasm screening for rust resistance and development of rust-resistant cultivars have been ongoing for several years in Asia $(13,15,26)$ and, more recently, in the United States $(5,22)$, South America (29,34), and Africa $(4,18,20)$. Genetic resources for resistance have been identified and have provided the resistance genes needed to breed rustresistant cultivars (14).

A key requirement in breeding efforts is the screening of plants for resistance to diverse pathogen populations to identify cultivars that are likely to withstand variable pathogen populations (14). Field screening has been a routine procedure $(7,18,20,27)$ for evaluating soybean genotypes for resistance to local rust populations. A number of studies also have evaluated soybean for rust resistance under greenhouse conditions using either field populations of the pathogen $(4,15)$ or specific pathogen isolates $(5,22)$. However, field screening can be carried out only once a year at most locations, is season dependent, and can be affected by uncontrollable environmental conditions such as temperature, humidity, and the simultaneous presence of other pathogens. The success of greenhouse screening depends on seedling age, inoculum quality and quantity, inoculation technique, and pre- and postinoculation environmental conditions. In addition, it is difficult to reliably screen a large number of germplasms against a wide range of pathogen populations in the greenhouse and under field conditions.

Growth-chamber evaluations, using detached leaves, have been used for resis- 
tance screening with facultative and obligate parasites $(2,24,31)$ and can overcome limitations posed by field and greenhouse screening. Thus, growth-chamber evaluations can facilitate mass and rapid germplasm screening, one of the key elements in plant-breeding programs. In soybean, Burdon and Marshal (9) used a detachedresistance of native Glycine spp. However, no formal comparison has been made between the effectiveness of field, greenhouse, and detached-leaf assays in screening soybean for rust resistance. Therefore, the main objective of this study was to standardize the detached-leaf method and conduct such a comparison, using germplasm with different resistance levels obtained from United States Department of Agriculture-Agricultural Research Service national Institute of Tropical Agriculture (IITA). We also examined rust resistance of some breeding lines developed elsewhere with previously known or unknown resistance under our conditions. If proven useful, the detached-leaf assay can facilitate rapid screening of germplasm against different pathogen populations simultaneously. Preliminary results on our use of been reported (4).

\section{MATERIALS AND METHODS}

Plant material. Fourteen soybean genotypes, including breeding lines with known and unknown resistance to soybean rust, were used in this study (Table 1). The breeding lines TGx 1485-1D and TGx 1440-1E and a local cv. Samsoy-2 were included as susceptible checks, and UG-5 was considered as a resistant check.

Inoculum preparation. Inoculum was obtained from naturally infected plants of the susceptible line TGx 1485-1D grown leaf assay to determine the levels of rust and breeding lines developed by the Interdetached-leaf assay for rust screening have

in a field plot, termed spore bank, earmarked for multiplying inoculum at the IITA research farm, Ibadan, Nigeria. Uredospores were harvested from the lower surface of infected leaves using a cyclone spore collector (G-R Manufacturing Company, Manhattan, KS) connected to a compressor that sucks spores by creating a vacuum in the unit. Spores were placed in 0.5-ml Eppendorf tubes and inoculum was neither monosporically derived nor purified. Spores were used for inoculation within $24 \mathrm{~h}$ after collection. The percentage of spores germinating was verified prior to inoculation by depositing spores on $2 \%$ water agar glass slides placed on top of water-soaked paper in petri plates and observing spore germination $24 \mathrm{~h}$ after incubation at $25^{\circ} \mathrm{C}(2)$.

Detached-leaf assay. Maintaining green color in leaves for the duration necessary to differentiate disease severity among genotypes is a problem often encountered when using detached leaves. Thus, the first experiment was designed to amend agar medium to prolong the green color of detached leaves. In the second experiment, an optimum spore concentration for inoculating detached leaves was determined. In the third experiment, an appropriate age of a leaf for use in the assay was determined. With the knowledge of type of amended medium, leaf age, and spore concentration, soybean genotypes were screened for their disease reaction using the detached-leaf assay in the fourth experiment. All four detached-leaf experiments described below were conducted twice.

Unless otherwise stated, the following standard method was used for the detached-leaf experiments. Fully expanded young leaves of the line TGx 1485-1D grown in the greenhouse were excised, washed in five to six changes of sterile distilled water, and cut into smaller pieces,

Table 1. Description of soybean accessions evaluated for resistance to Phakopsora pachyrhizi (soybean rust) at the International Institute of Tropical Agriculture, Ibadan, Nigeria

\begin{tabular}{lllcl}
\hline Soybean lines & \multicolumn{1}{c}{ Source $^{\mathbf{x}}$} & Origin & Flower color & Maturity $^{\mathbf{y}}$ \\
\hline PI 594538A & USDA-ARS & China & White & Early \\
PI 417089A & USDA-ARS & Japan & Purple & Medium \\
UG-5 & NARO & Uganda & Purple & Early \\
GC 00138-29 & NARO & Uganda & Purple & Medium \\
PI 368039 & USDA-ARS & Taiwan & White & Early \\
PI 462312 & USDA-ARS & India & White & Medium \\
TGx 1835-10E & IITA & Nigeria & Purple & Early \\
TGx 1903-3F & IITA & Nigeria & Purple & Early \\
TGx 1891-3F & IITA & Nigeria & White & Medium \\
TGx 1895-49F & IITA & Nigeria & White & Early \\
TGx 1864-17F & IITA & Nigeria & Purple & Late \\
TGx 1440-1E & IITA & Nigeria & Purple & Late \\
TGx 1485-1D & IITA & Nigeria & Purple & Early \\
Samsoy-2 & IITA & Nigeria & Purple & Medium \\
\hline
\end{tabular}

${ }^{x}$ Original seed sources: United States Department of Agriculture-Agricultural Research Service (USDA-ARS) Plant Genetic Resources Unit, Soybean/Maize Germ plasm, Pathology and Genetics Research Unit, Urbana, IL; International Institute of Tropical Agriculture (IITA) Soybean Breeding Unit, Ibadan, Nigeria; and National Agriculture Research Organization (NARO), Kampala, Uganda.

${ }^{\mathrm{y}}$ Maturity levels: early $=<90$ days to maturity, medium $=91$ to 100 days to maturity, and late $=>100$ days to maturity.

${ }^{\mathrm{z}}$ Susceptible breeding lines (TGx 1485-1D and TGx 1440-1E) and a local check (Samsoy-2). each measuring $5 \mathrm{~cm}$ long by $5 \mathrm{~cm}$ wide. The leaf pieces were spread on sterile paper towels in a laminar flow hood and the abaxial surface was sprayed with $400 \mu \mathrm{l}$ of spore suspension using an atomizer attached to an air compressor. A single leaf piece was carefully placed in a 9-cmdiameter petri dish with adaxial side appressed on $1 \%$ technical agar (Oxoid, Unipath Ltd., Basingstoke, Hampshire, England) amended with kinetin at $10 \mu \mathrm{g} / \mathrm{ml}$ prior to sterilization. Lactic acid (1.5 $\mathrm{ml} /$ liter) and benomyl (12.5 mg/liter) were added to agar medium to inhibit growth of saprophytic fungi and bacteria. Petri dishes containing leaf pieces were incubated at $20^{\circ} \mathrm{C}$ with a cycle of $12 \mathrm{~h}$ of light and $12 \mathrm{~h}$ of dark, but were not sealed with Parafilm.

Effect of agar amendment. Five plant hormones and sucrose were evaluated at different concentrations in $1 \%$ technical agar medium. The concentrations tested were 5 and $15 \mu \mathrm{g} / \mathrm{ml}$ for gibberellic acid; 10,20 , and $50 \mu \mathrm{g} / \mathrm{ml}$ for kinetin; 20,40 , and $60 \mu \mathrm{g} / \mathrm{ml}$ for benzimidazole; $3 \mu \mathrm{g} / \mathrm{ml}$ for indole butyric acid (IBA); and 10, 25, and $50 \mu \mathrm{g} / \mathrm{ml}$ for sucrose. Plant hormones were added to agar medium following autoclaving but immediately before dispensing, except for kinetin, which was added before autoclaving. Nonamended technical agar medium was used as a control. Petri dishes with leaf pieces (one per plate) on treatment media were arranged in the incubator in a completely randomized design with six replications. Leaves were rated for percentage of green color against a color chart from 2 until 18 days after plating at 2- to 4-day intervals, using a 1to-9 chlorosis scale in which $1=0$ to $5 \%$ chlorosis (i.e., 95 to $100 \%$ green color), 2 $=5$ to $20,3=20$ to $30,4=30$ to $40,5=$ 40 to $50,6=50$ to $60,7=60$ to $70,8=70$ to 80 , and $9=>80 \%$ chlorosis ( 30 ).

Effect of inoculum concentrations. Spores were suspended in sterile distilled water and, using four hemacytometer counts, the resulting suspension was appropriately diluted with sterile distilled water, to $1 \times 10^{2}, 1 \times 10^{3}, 1 \times 10^{4}, 1 \times 10^{5}$, and $1 \times 10^{6}$ spores $/ \mathrm{ml}$ of water. Using the standard method for detached-leaf assay described above, leaf pieces were inoculated to evaluate the five inoculum concentrations. The inoculated leaf pieces and a noninoculated control were incubated in a completely randomized design with three replications. Data on total number of pustules within a $1-\mathrm{cm}^{2}$ area of the leaf was recorded under a dissecting microscope $(\times 20$ magnification) 17 days after inoculation. The same $1-\mathrm{cm}^{2}$ leaf area then was excised, placed in a vial containing $2 \mathrm{ml}$ of water, shaken thoroughly in a magnetic stirrer to dislodge the spores, and the number of spores counted using a hemacytometer. The total number of spores was divided by the number of pustules in the same $1-\mathrm{cm}^{2}$ leaf area to determine the number of spores per pustule. 
Effect of leaf age. Two sets of leaves of TGx 1485-1D and TGx 1448-2E that were 1 to 2,3 to 4 , and 5 to 6 weeks old were used to determine the effect of leaf age on duration of green color and a suitable age at which to inoculate detached leaves. Leaf age was determined based on time of leaf emergence, and the middle leaflet of each leaf was used for inoculation. The standard inoculation method described above was followed for both sets of leaves, except that the first set was not inoculated whereas the second set was inoculated. Petri dishes with leaf pieces of the three age groups were arranged in an incubator in a completely randomized design with three replications (three leaf pieces, one leaf per plate). For the noninoculated set, leaves were rated for percentage of green color against a color chart as described above using the 1-to-9 chlorosis scale (30) until 18 days after leaf plating. For the inoculated set, data were collected on: days to lesion appearance, days to pustule formation, days to pustule eruption, number of pustules, and spores per pustule in a $1-\mathrm{cm}^{2}$ leaf area. Leaves were observed daily under a dissecting microscope at $\times 20$ magnification to record the first three parameters. Sporulation was determined 18 days after inoculation in the same $1-\mathrm{cm}^{2}$ leaf area in which pustule numbers were counted a day earlier. The $1-\mathrm{cm}^{2}$ leaf area was excised, immersed in $2 \mathrm{ml}$ of sterile water, shaken vigorously for 1 min using a vortex mixture to dislodge the spores, and the number of spores counted using a hemacytometer. The number of spores per pustule was calculated as described above.

Germplasm evaluation. The detachedleaf assay was evaluated for ability to discern differences in levels of resistance to $P$. pachyrhizi among 14 genotypes obtained from diverse sources (Table 1). Three- to four-week-old leaves were obtained from plants in the greenhouse and leaf pieces of all genotypes prepared following the standard method for detached-leaf assay and inoculated with $1 \times 10^{5}$ spores $/ \mathrm{ml}$ of water as described above. Petri dishes containing inoculated leaf pieces of each genotype were arranged in the incubator in a completely randomized design with three replications (three plates per genotype, one leaf per plate). Observations on inoculated detached leaves commenced 1 day after inoculation and continued for 21 days. Data were collected on: days to lesion appearance, days to pustule formation, days to pustule eruption, lesion number, lesion diameter, lesion type, and number of pustules and spores per pustule in a $1-\mathrm{cm}^{2}$ leaf area. Lesion diameter and lesion type were recorded 12 days after inoculation, whereas lesion numbers were recorded 17 days after inoculation.

Greenhouse screening. Seed of the 14 soybean lines were sown in $18-\mathrm{cm}-$ diameter plastic pots (two pots per line and four seeds per pot) in a greenhouse. Seed- lings were thinned to two plants per pot after emergence and fertilized only once at V3 stage with NPK $(15: 15: 15)$ at the rate of $3 \mathrm{~g} /$ pot. Inoculum was freshly obtained from the spore bank and prepared as described above. At the V4 stage, about 4 weeks after planting, one fully expanded trifoliate leaf from each plant was inoculated on the abaxial side with $1.5 \mathrm{ml}$ of $1 \times$ $10^{5}$ urediniospores $/ \mathrm{ml}$ of sterile distilled water using a hand sprayer. Treatments were arranged in a completely randomized design with one pot serving as a replication. After inoculation, inoculated plants were covered by a polyethylene bag and adequate relative humidity and temperature for infection was provided by a fogging machine (Reldair Fogging System; Reldair bv, Edisonstraat, The Netherlands) for 12 successive hours. Polyethylene bags were removed thereafter and leaf wetness was maintained by a cycle of $10 \mathrm{~min}$ of fogging after every $40 \mathrm{~min}$ for 3 days. Observations were made from the middle leaflet of the inoculated trifoliate leaves starting 2 days after inoculation until 21 days later. Days to lesion appearance, days to pustule formation, days to pustule eruption, lesion number, lesion diameter, lesion type, number of pustules, and spores per pustule in a $1-\mathrm{cm}^{2}$ leaf area were recorded. In addition, disease severity (percentage of diseased area of the middle leaflet of the inoculated leaf of each plant) was recorded 21 days after inoculation. The experiment was conducted twice.

Field screening. The first experiment was designed to determine the number of rows of a test line that can be surrounded with an infector row to ensure high and uniform disease pressure on the test line plants. The highly susceptible breeding line TGx 1910-2F was used as the infector row and susceptible TGx 1448-2E was used as the test line. The infector row trial was conducted for 2 years at the IITA experimental field, Ibadan, Nigeria. Seed of the test genotype was sown on 24 and 30 September 2005 and 2006, respectively, for the first and second field experiments. In both years, seed of the infector row was sown 2 weeks prior to sowing seed for the test line. In each year, treatments were one, three, five, and seven rows of the test genotype surrounded by infector rows and were evaluated to determine their effectiveness in providing uniform and high disease pressure. Rows of the test line were $5 \mathrm{~m}$ long and surrounded with an infector row $0.5 \mathrm{~m}$ long at both ends and $6 \mathrm{~m}$ long on the adjacent sides. Inoculum was freshly obtained and prepared as described above and the infector row plants were inoculated at V5 when plants of test lines were at V3 growth stage. A plot with seven test rows without any surrounding infector rows served as the control treatment.

Prior to inoculation, plants of the test line were covered using a polyethylene sheet to ensure that inoculum originated primarily from infector plants. A spore concentration of $1 \times 10^{6}$ urediniospores $/ \mathrm{ml}$ of sterile distilled water containing one drop of Tween 20 was applied to the abaxial side of the leaves of the infector plants using a 20-liter knapsack sprayer (Cooper Pegler, Burgess Hill, Sussex, UK) at growth stage V5 and R1. In both years, treatments were arranged in a completely randomized block design with three replications. To minimize interplot interference, treatment plots within a replication were separated from each other by 2 rows of maize while 1-m-long buffer of a maize crop separated replications. Entire plant disease severity (percentage of diseased leaf area) was recorded when test plants were at growth stage R6. Whole plant disease severity was obtained by taking the average disease severity for three individual middle leaflets of leaves selected from the bottom, middle, and upper layers of the plant.

Fourteen soybean lines (Table 1) were evaluated for resistance to soybean rust using TGx 1485-1D as the infector row. Seed of test lines were sown on 23 September 2005 and 23 August 2006 in a 2-m row at a spacing of $0.75 \mathrm{~cm}$ between rows and $20 \mathrm{~cm}$ between plants. Treatment plots were arranged in a completely randomized block design with three replications. Seed for the infector plants were sown 2 weeks before sowing seed for the 14 soybean lines and infector plants were placed after every three rows of the treatment lines. Inoculum source and inoculation were as described in the first experiment. Data on disease severity were recorded on 10 randomly selected test plants in each plot as described in the first experiment. A sample size of 50 lesions was used to determine the percentage of sporulation by counting the number of lesions with uredinia and expressing this as the percentage of the total sample size.

Statistical analysis. Prior to analysis, data from all four detached-leaf experiments recorded from the two runs were subjected to analysis of variance (ANOVA) to test for homogeneity of error variance (12). No heterogeneity in the data was detected and data were pooled over runs for final analysis and presentation. Data recorded from the experiment to determine a suitable concentration of inoculum for inoculation were subjected to analysis of variance using the PROC GLM procedure of SAS (SAS Institute Inc., Cary, NC). The effect of plant hormones and leaf age on maintaining the green color of detached leaves over time was analyzed by repeated measures analysis of variance with the SAS GLM procedure. The effect of leaf age and genotypes on days to lesion appearance, days to pustule formation, days to pustule eruption, number of pustules, and spores per pustule (disease parameters) was analyzed using the PROC GLM procedure of SAS and means were sepa- 


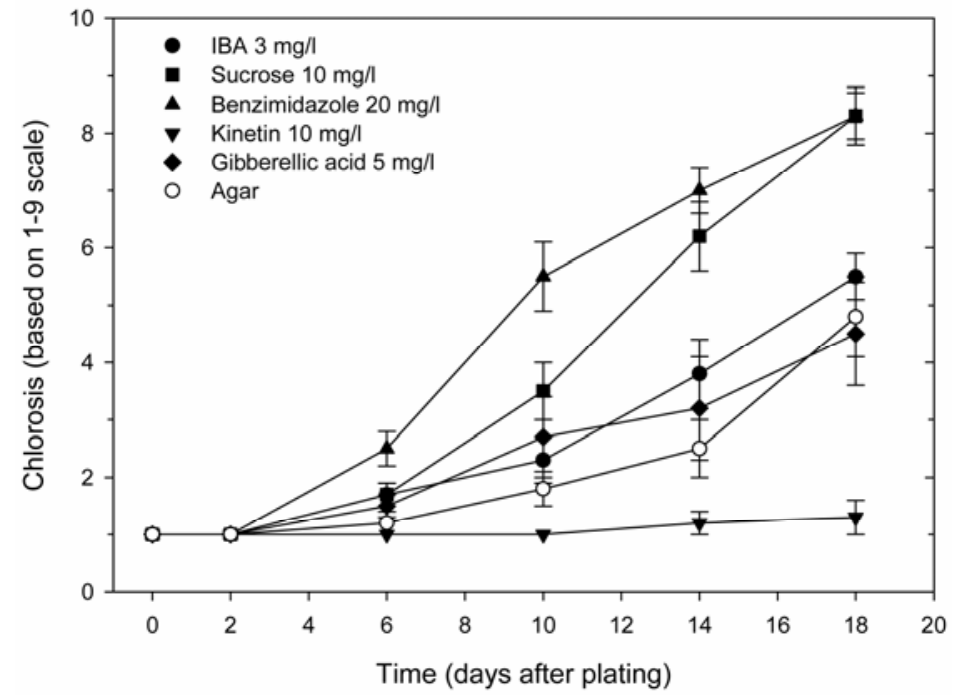

Fig. 1. Effect of agar media amended with different concentrations of plant hormones in maintaining green color in detached leaves of the soybean breeding line TGx 1485-1D. For each concentration, vertical bars represent standard errors of mean percent chlorosis. Leaves were rated for percentage of green color against a color chart, using a 1-to- 9 chlorosis scale in which $1=0$ to $5 \%$ chlorosis (i.e., 95 to $100 \%$ green color), $2=5$ to $20,3=20$ to $30,4=30$ to $40,5=40$ to $50,6=50$ to $60,7=60$ to 70,8 $=70$ to 80 , and $9=>80 \%$ chlorosis.
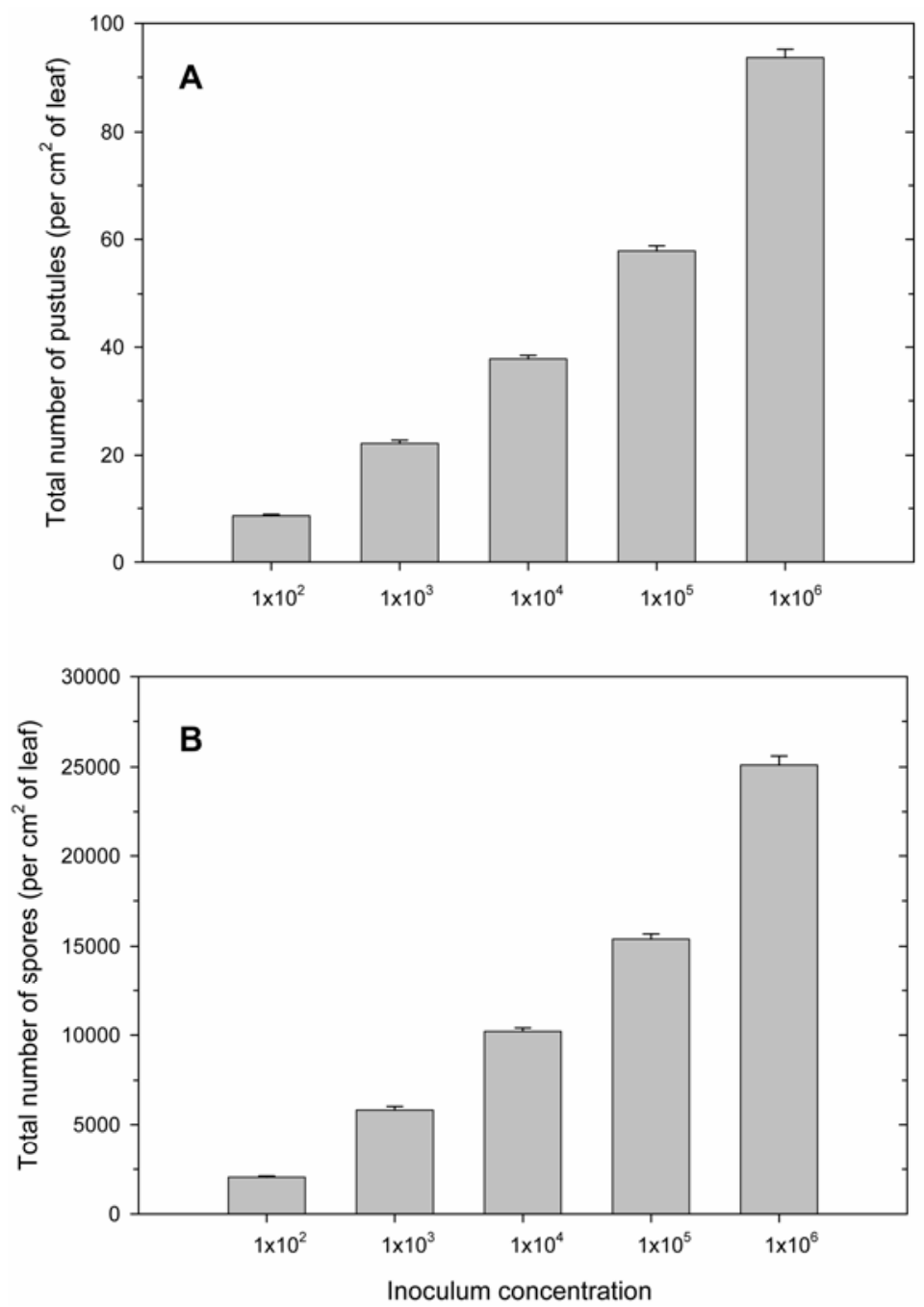

Fig. 2. Effect of different concentrations of Phakopsora pachyrhizi inoculum (urediniospores per milliliter) on $\mathbf{A}$, number of pustules and $\mathbf{B}$, number of spores per unit area of detached leaf of the soybean breeding line TGx 1485-1D. For each vertical bar, vertical lines represent the standard error of the mean. rated using Fisher's protected least significant difference (LSD) test at $\alpha=0.05$.

Greenhouse data recorded on the 14 soybean lines from the two runs was similarly subjected to ANOVA to test for homogeneity of error variance. No heterogeneity in the data was detected and pooled data over runs were used for final analysis and presentation. The effects of soybean lines evaluated for resistance using the detached-leaf assay and in the greenhouse and field on disease parameters were analyzed separately using the PROC GLM procedure of SAS and means were separated using LSD. Data collected on the effect of infector row on disease severity were similarly subjected to ANOVA, except that means were compared using Student-Newman-Keuls test at $\alpha=0.05$. Pearson's correlation coefficients for disease parameters recorded during evaluation of the 14 soybean lines were computed using PROC CORR procedure of SAS to compare the effectiveness of detached-leaf, greenhouse, and field methods in screening soybean for rust resistance. For field data, there was no significant genotype-year interaction and combined disease severity and sporulation data was used in the correlation analysis. All analyses were performed using SAS version 9.1.

\section{RESULTS}

Evaluation of amended media on detached leaves. Area of green color was used as a measure of deterioration of detached leaves over time. Amended media significantly $(P<0.0001)$ affected the amount of chlorosis, with distinct differences being observed as early as 6 days after plating. From 10 days after plating, leaves plated on media amended with kinetin at $10 \mathrm{mg} / \mathrm{liter}$ consistently had the lowest amount of chlorosis compared with leaves plated on media amended with all other plant hormones (Fig. 1). By 18 days after plating, the amount of chlorosis in leaves plated on kinetin-amended medium was $<5 \%$, which was significantly $(P<$ $0.05)$ lower than that of leaves plated on media amended with all other plant hormones. The corresponding level of chlorosis for leaves plated on the nonamended medium was about $50 \%$.

Inoculum concentration. Inoculation of leaves of TGx 1485-1D with variable concentrations of rust spores resulted in significantly $(P<0.0001)$ different numbers of pustules and spores per unit leaf area. The total number of pustules and spores in a unit area increased linearly with increasing levels of inoculum concentration (Fig. 2). These two disease variables were lowest and highest when detached leaves were inoculated with $1 \times 10^{2}$ and $1 \times 10^{6}$ spores/ $\mathrm{ml}$, respectively.

Age of detached leaves. The levels of chlorosis of leaves plated on kinetinamended medium were significantly $(P<$ 0.0001 ) affected by the age of detached 
leaf. For both TGx 1485-1D and TGx 1448-2E, leaves that were 3 to 4 weeks old had significantly $(P<0.05)$ lower levels of chlorosis than leaves that were either 1 to 2 or 5 to 6 weeks old. These differences were observed starting from 10 days after plating until 18 days later (Fig. 3). At 18 days after plating, the amount of chlorosis in 3- to 4-week-old leaves was $<5 \%$, whereas the corresponding levels of chlorosis for 1- to 2- and 5- to 6-week-old leaves were 50 and $70 \%$, respectively.

Age of detached leaves used for inoculation did not significantly $(P>0.05)$ affect days to lesion appearance, days to pustule formation, and days to pustule eruption in both cultivars and number of pustules per unit area and number of spores per pustule in TGx 1448-2E (Table 2). However, inoculation of leaves of TGx 1485-1D that were 3 to 4 weeks old resulted in a significantly larger number of pustules $(P=$ $0.0146)$ and number of spores per pustule $(P=0.0088)$ compared with leaves that were either 1 to 2 or 5 to 6 weeks old at the time of inoculation.

Detached-leaf screening. Soybean lines significantly $(P<0.0001)$ affected all the disease parameters that were recorded when genotypes were screened for resistance using the detached-leaf assay (Table 3). Lines PI 594538A, PI 417089A, and UG-5 required significantly $(P<0.05)$ more days for lesion appearance, pustule formation, and pustule eruption compared with the local check Samsoy-2 and the susceptible check TGx 1485-1D. Lesions appeared 2 days earlier on the susceptible checks compared with PI 594538A and PI 417089A. No pustules were formed on leaves of line PI 594538A following inoculation (Table 2). However, compared with the susceptible checks, pustules formed and erupted about 7 and 10 days later on UG-5 and PI 417089A, respectively. A significantly $(P<0.05)$ smaller number of lesions, pustules per lesion, and spores per pustule was observed on PI 594538A and soybean lines with $\mathrm{RB}$ reaction compared with the two check lines that had large values and TAN reactions. Lesion diameter was significantly $(P<0.05)$ smaller on PI 594538A than all the other lines, and genotypes with RB reaction had larger lesions compared with lines with TAN reaction.

Greenhouse screening. Disease parameters differed significantly $(P<$ 0.0001) among the soybean lines when they were evaluated for rust resistance (Table 4). As was the case with the detached-leaf assay, no pustules were observed on PI 594538A when it was evaluated in the greenhouse. Compared with the two checks, pustules formed and erupted about 10 days later on PI 417089A. Soybean lines that had significantly longer time to pustule formation and eruption $(>5$ days) than the checks were UG-5, GC 00138-29, PI 368039, and PI 462312. Number of lesions per unit area, pustules per lesion, and spores per pustule followed a pattern similar to that observed in the detached-leaf assay, with PI 594538A, PI 417089A, and UG-5 being the most resistant. Similarly, lesion diameter was significantly $(P<0.05)$ smaller for PI 594538A than all the other remaining lines. All the lines with RB reaction had significantly $(P$ $<0.05$ ) fewer pustules per lesion and spores per pustule, and larger lesion diameters, compared with lines with TAN reaction. Disease severity on PI 594538A was about $0.1 \%$ and was significantly $(P<$
0.05) lower than that recorded on all the remaining genotypes except PI 417089A. Disease severity observed on the control checks, TGx 1485-1D and Samsoy-2, was about $60 \%$.

Field screening. In both years, the number of test line rows surrounded by an infector row influenced the uniformity and the amount of disease severity on the test line plants (Table 5). No significant $(P>$ $0.05)$ differences in disease severity were observed among test line plants when the infector surrounded three rows of the test

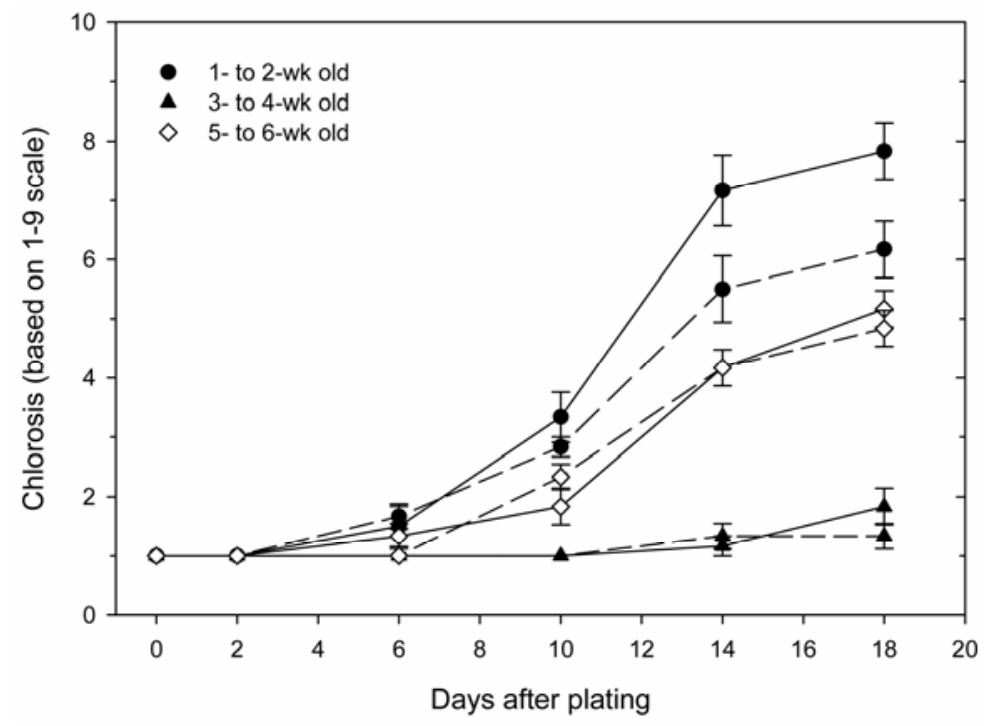

Fig. 3. Effect of leaf age on maintaining green color in detached leaves of the soybean breeding lines TGx 1485-1D (solid line) and TGx 1448-2E (dashed line). For each breeding line, vertical bars represent standard errors of mean percentage chlorosis.

Table 2. Effect of age of detached leaf on disease parameters during assessment of soybean rust caused by Phakopsora pachyrhizi, using the detached-leaf technique

\begin{tabular}{|c|c|c|}
\hline \multirow[b]{2}{*}{ Parameter, leaf age (weeks) ${ }^{\mathrm{z}}$} & \multicolumn{2}{|c|}{ Soybean line ${ }^{y}$} \\
\hline & TGx 1485-1D & TGx 1448-2E \\
\hline \multicolumn{3}{|l|}{ Lesion appearance (DAI) } \\
\hline $1-2$ & 4 & 5 \\
\hline $3-4$ & 4 & 5 \\
\hline $5-6$ & 4 & 5 \\
\hline $\operatorname{LSD}(0.05)$ & ns & ns \\
\hline \multicolumn{3}{|l|}{ Pustule formation (DAI) } \\
\hline $1-2$ & 7 & 8 \\
\hline $3-4$ & 7 & 8 \\
\hline $5-6$ & 7 & 8 \\
\hline LSD (0.05) & ns & ns \\
\hline \multicolumn{3}{|l|}{ Pustule eruption (DAI) } \\
\hline $1-2$ & 9 & 11 \\
\hline $3-4$ & 9 & 11 \\
\hline $5-6$ & 9 & 11 \\
\hline LSD (0.05) & $\mathrm{ns}$ & ns \\
\hline \multicolumn{3}{|c|}{ Number of pustules $/ \mathrm{cm}^{2}$ (17 DAI) } \\
\hline $1-2$ & 36 & 23 \\
\hline $3-4$ & 43 & 24 \\
\hline $5-6$ & 35 & 19 \\
\hline LSD (0.05) & 5.2 & ns \\
\hline \multicolumn{3}{|c|}{ Number of spores per pustule (18 DAI) } \\
\hline $1-2$ & 348 & 363 \\
\hline $3-4$ & 372 & 355 \\
\hline $5-6$ & 335 & 359 \\
\hline $\operatorname{LSD}(0.05)$ & 23.4 & ns \\
\hline
\end{tabular}

${ }^{\mathrm{y}}$ Disease parameter values were not significantly different between the first and second runs and values shown are for combined data; ns $=$ not significant at $P<0.05$.

${ }^{\mathrm{z}} \mathrm{DAI}=$ days after inoculation and $\mathrm{LSD}=$ least significant difference. 
line. In contrast, significant $(P<0.0001)$ differences in disease severity were observed among test line plants when infector rows surrounded five and seven rows of the test line. Similarly, significant $(P<$ $0.001)$ differences in disease severity were observed among test line plants in the control plots where seven test line rows were not surrounded by infector rows. Although disease severity was higher in 2004 than in 2005, disease severity in both years was higher in plots where the infector row surrounded three rows of the test line and lowest in the control plots.

Highly significant $(P<0.0001)$ differences in disease severity and sporulation were observed among the 14 soybean lines when evaluated for resistance in the field
(Table 6). As was the case with the greenhouse evaluations, PI 594538A, PI 417089A, and UG-5 were the most resistant, with disease severity levels $(<2 \%)$ significantly $(P<0.05)$ lower than disease levels observed on the other lines. Among the breeding lines, TGx 1835-10E had the lowest disease severity $(<8 \%)$, while three other TGx breeding lines (1903-3F, 1864$17 \mathrm{~F}$, and $1891-3 \mathrm{~F}$ ) had up to $15 \%$ diseased leaf area. Disease severity observed on the susceptible checks was $>50 \%$. Soybean lines PI 594538A, PI 417089A, and UG-5 had also the lowest levels of sporulation, ranging from 0 to $10 \%$. Apart from TGx 1835-10E, all the breeding lines and the local check Samsoy-2 had 100\% sporulation (Table 6). No reaction was observed on PI 594538A, whereas all the remaining PI accessions, UG-5, and GC 00138-29 had RB lesion type. All the breeding lines and the local check had TAN lesions except TGx 1835-10E, which had RB lesions.

Relationship among field, greenhouse, and detached-leaf evaluations. There were significant $(P<0.05)$ correlations between field and greenhouse results, with correlation coefficients ranging from 0.57 to 0.99 (Table 7). The highest correlation coefficients were observed between disease severity in the field and pustules per lesion $(r=0.77, P=0.0011)$, spores per pustule $(r=0.88, P<0.0001)$, and disease severity $(r=0.99, P<0.0001)$ in the greenhouse. Sporulation under field condi-

Table 3. Infection parameters of soybean lines evaluated for resistance to rust (Phakopsora pachyrhizi) following inoculation of detached leaves in petridishes $^{\mathrm{w}}$

\begin{tabular}{|c|c|c|c|c|c|c|c|c|}
\hline \multirow[b]{2}{*}{ Soybean lines } & \multicolumn{3}{|c|}{ Number of days to ${ }^{x}$} & \multirow[b]{2}{*}{ Lesions $/ \mathbf{c m}^{2}$} & \multirow[b]{2}{*}{ Pustules/lesion } & \multirow[b]{2}{*}{ Spores/pustule } & \multicolumn{2}{|c|}{ Lesion } \\
\hline & LA & $\mathbf{P F}$ & PE & & & & Diameter $(\mu \mathrm{m})$ & Type \\
\hline PI 594538A & 7 & - & - & 9.1 & 0.0 & 0 & 171 & HS \\
\hline PI 417089A & 7 & 16.6 & 19.0 & 10.1 & 0.4 & 42 & 485 & $\mathrm{RB}$ \\
\hline UG-5 & 7 & 14.2 & 16.2 & 7.9 & 1.0 & 60 & 352 & $\mathrm{RB}$ \\
\hline GC 00138-29 & 6 & 11.9 & 19.3 & 11.6 & 1.1 & 89 & 565 & $\mathrm{RB}$ \\
\hline PI 368039 & 6 & 13.4 & 15.4 & 9.0 & 0.8 & 81 & 537 & $\mathrm{RB}$ \\
\hline PI 462312 & 5 & 13.7 & 15.6 & 16.3 & 1.2 & 58 & 475 & RB \\
\hline TGx 1835-10E & 5 & 10.3 & 12.3 & 15.1 & 1.5 & 98 & 658 & $\mathrm{RB}$ \\
\hline TGx 1903-3F & 5 & 7.9 & 10.8 & 24.2 & 2.2 & 194 & 260 & TAN \\
\hline TGx 1891-3F & 7 & 9.4 & 12.3 & 12.9 & 2.2 & 178 & 224 & TAN \\
\hline TGx 1895-49F & 5 & 7.4 & 10.3 & 20.7 & 2.4 & 197 & 220 & TAN \\
\hline TGx 1864-17F & 5 & 7.3 & 10.3 & 18.4 & 2.8 & 200 & 270 & TAN \\
\hline TGx $1440-1 E^{z}$ & 5 & 7.0 & 9.0 & 18.2 & 2.6 & 285 & 228 & TAN \\
\hline TGx $1485-1 D^{z}$ & 5 & 7.2 & 10.1 & 27.6 & 2.9 & 318 & 344 & TAN \\
\hline Samsoy-2z & 5 & 7.0 & 9.0 & 27.4 & 3.0 & 328 & 372 & TAN \\
\hline $\operatorname{LSD}(\alpha=0.05)$ & 0.1 & 0.3 & 2.6 & 3.2 & 0.4 & 22.9 & 34.5 & $\ldots$ \\
\hline
\end{tabular}

${ }^{\mathrm{w}}$ Disease data from the first and second runs were not significantly different and values shown are for combined data. LSD $=$ least significant difference and $-=$ no pustule formation.

${ }^{x} \mathrm{LA}, \mathrm{PF}$, and $\mathrm{PE}=$ lesion appearance, pustule formation, and pustule eruption, respectively.

${ }^{y} \mathrm{HS}=$ small, hypersensitive, pinhead-like specks; $\mathrm{RB}=$ reddish brown hypersensitive lesions with 0 to 6 pustules per lesion; and TAN = tan-colored lesions with 1 to 14 pustules per lesion.

${ }^{\mathrm{z}}$ Susceptible breeding lines (TGx 1485-1D and TGx 1440-1E) and a local check (Samsoy-2).

Table 4. Infection parameters of soybean lines artificially inoculated with Phakopsora pachyrhizi to evaluate for rust resistance under greenhouse conditions ${ }^{\mathrm{v}}$

\begin{tabular}{|c|c|c|c|c|c|c|c|c|c|}
\hline \multirow[b]{2}{*}{ Soybean lines } & \multicolumn{3}{|c|}{ Number of days to ${ }^{w}$} & \multirow[b]{2}{*}{ Lesions $/ \mathrm{cm}^{2}$} & \multirow[b]{2}{*}{ Pustules/lesion } & \multirow[b]{2}{*}{ Spores/pustule } & \multirow[b]{2}{*}{ Lesion diameter $(\mu \mathrm{m})$} & \multirow[b]{2}{*}{$\operatorname{DS}(\%)^{\mathrm{x}}$} & \multirow[b]{2}{*}{ Lesion type $^{\mathrm{y}}$} \\
\hline & LA & PF & $\mathbf{P E}$ & & & & & & \\
\hline PI 594538A & 7.0 & - & - & 3.5 & 0.0 & 0 & 280 & 0.1 & HS \\
\hline PI 417089A & 7.0 & 17.5 & 19.5 & 2.8 & 0.6 & 49 & 656 & 2.6 & $\mathrm{RB}$ \\
\hline UG-5 & 6.0 & 14.5 & 16.5 & 4.9 & 1.4 & 66 & 682 & 5.6 & $\mathrm{RB}$ \\
\hline GC 00138-29 & 6.0 & 11.6 & 14.0 & 12.5 & 1.4 & 115 & 581 & 11.2 & $\mathrm{RB}$ \\
\hline PI 368039 & 6.0 & 15.0 & 17.0 & 5.9 & 1.1 & 100 & 694 & 8.7 & $\mathrm{RB}$ \\
\hline PI 462312 & 5.0 & 13.9 & 16.0 & 11.4 & 1.5 & 66 & 689 & 6.9 & $\mathrm{RB}$ \\
\hline TGx 1835-10E & 5.0 & 9.1 & 11.2 & 27.8 & 1.6 & 132 & 584 & 15.0 & $\mathrm{RB}$ \\
\hline TGx 1903-3F & 5.0 & 7.0 & 9.0 & 25.8 & 2.4 & 277 & 370 & 21.4 & TAN \\
\hline TGx 1891-3F & 6.0 & 8.3 & 10.3 & 20.6 & 2.3 & 227 & 352 & 15.2 & TAN \\
\hline TGx 1895-49F & 5.0 & 7.0 & 9.0 & 25.7 & 3.0 & 263 & 365 & 14.5 & TAN \\
\hline TGx 1864-17F & 5.8 & 7.5 & 9.5 & 22.0 & 3.4 & 253 & 327 & 17.8 & TAN \\
\hline TGx 1440-1E & 5.0 & 7.5 & 9.5 & 24.2 & 3.6 & 403 & 299 & 53.2 & TAN \\
\hline TGx $1485-1 D^{z}$ & 5.0 & 7.0 & 9.0 & 31.5 & 3.5 & 405 & 387 & 60.5 & TAN \\
\hline Samsoy-2z & 5.0 & 7.0 & 9.0 & 27.6 & 3.5 & 405 & 416 & 60.6 & TAN \\
\hline $\operatorname{LSD}(\alpha=0.05)$ & 0.1 & 0.6 & 0.6 & 7.3 & 0.4 & 30 & 46 & 5.4 & $\ldots$ \\
\hline
\end{tabular}

${ }^{\mathrm{v}}$ Disease data from the first and second runs were not significantly different and values shown are for combined data. LSD $=$ least significant difference and $-=$ no pustule formation.

${ }^{\mathrm{w}} \mathrm{LA}, \mathrm{PF}$, and $\mathrm{PE}=$ lesion appearance, pustule formation, and pustule eruption, respectively.

${ }^{x}$ DS $=$ disease severity (diseased leaf area).

${ }^{y} \mathrm{HS}=$ small, hypersensitive, pinhead-like specks; RB = reddish brown hypersensitive lesions with 0 to 6 pustules per lesion; and TAN = tan-colored lesions with 1 to 14 pustules per lesion.

${ }^{\mathrm{z}}$ Susceptible breeding lines (TGx 1485-1D and TGx 1440-1E) and a local check (Samsoy-2). 
tion also was strongly correlated with all disease parameters in the greenhouse evaluation (absolute $r$ ranging from 0.64 to $0.91, P<0.01$ ). Disease severity and sporulation in the field were not significantly correlated to lesion diameter in greenhouse evaluations.

Similarly, there were significant $(P<$ $0.05)$ correlations between field and detached-leaf evaluations, with correlation coefficients ranging from 0.55 to 0.92 (Table 7). Disease severity in the field was significantly correlated with the detachedleaf data on number of lesions, pustules per lesion, and spores per pustule $(r=0.74$ to $0.89, P<0.01)$. Field sporulation also was similarly correlated with all the infection parameters in detached-leaf assay $(r=$ 0.76 to $0.91, P<0.01$ ), except for lesion diameter.

Highly significant $(P<0.01)$ correlations were observed between greenhouse and detached-leaf screening data, with correlation coefficients ranging from 0.72 to 0.99 (Table 7), except for the correlation between days to lesion appearance in the detached-leaf and days to pustule formation ( $r=0.65, P=0.0172)$, days to pustule eruption $(r=0.64, P=0.0178)$, spores per pustule $(r=-0.64, P=0.0136)$, and disease severity ( $r=-0.57, P=0.0323)$ in the greenhouse. Disease severity in the greenhouse was significantly $(P<0.01)$ correlated with all parameters in the detachedleaf assay except for days to lesion appearance (Table 7).

\section{DISCUSSION}

Breeding soybean for rust resistance requires appropriate disease screening methodologies. Most commonly, screening of genotypes has been conducted under field conditions; however, field screening has limitations, because it depends on natural occurrence of suitable environmental conditions and pathogen inoculum. In addition, field screening often can be conducted only once in a year. Similarly, screening of genotypes under greenhouse conditions also requires proper conditions for disease development and only a limited number of lines can be evaluated due to space limitations. More often, such limitations restrict rapid progress in breeding plants for disease resistance. Direct inoculation of detached leaves in moist chambers is an assay that overcomes the limitations associated time and space dependency of field and greenhouse evaluations of genotypes for disease resistance. In this study, we showed that the detached-leaf assay is a reliable and rapid method to discriminate rust resistance in soybean in the laboratory in a short period of time, while providing conditions for uniform inoculum levels. In a range of lines with variable levels of resistance, different infection parameters were similar in the detached-leaf assay and evaluations under greenhouse and field conditions. Several germplasm and breeding lines with rust resistance were identified using these screening methods.

Appropriate in vitro conditions were determined for the detached-leaf assay to maximize differences in disease resistance components among soybean lines. A critical aspect of the detached-leaf assay is the

Table 6. Infection of soybean lines evaluated for resistance to soybean rust caused by Phakopsora pachyrhizi, under field conditions at the International Institute of Tropical Agriculture research farm at Ibadan, Nigeria

\begin{tabular}{|c|c|c|c|c|c|}
\hline \multirow[b]{2}{*}{ Soybean line $e^{x}$} & \multicolumn{2}{|r|}{2005} & \multicolumn{2}{|r|}{2006} & \multirow[b]{2}{*}{ Lesion type $^{z}$} \\
\hline & $\operatorname{DS}(\%)^{\mathrm{y}}$ & Sporulation (\%) & DS (\%) & Sporulation (\%) & \\
\hline PI 594538A & 0.1 & 0 & 0.1 & 0 & No reaction \\
\hline PI 417089A & 0.2 & 4 & 0.6 & 6 & $\mathrm{RB}$ \\
\hline UG-5 & 1.7 & 6 & 2.4 & 10 & $\mathrm{RB}$ \\
\hline GC 00138-29 & 7.9 & 57 & 9.7 & 64 & $\mathrm{RB}$ \\
\hline PI 368039 & 8.1 & 53 & 7.6 & 47 & $\mathrm{RB}$ \\
\hline PI 462312 & 11.8 & 72 & 9.1 & 67 & $\mathrm{RB}$ \\
\hline TGx 1835-10E & 4.9 & 72 & 7.8 & 66 & $\mathrm{RB}$ \\
\hline TGx 1903-3F & 11.6 & 100 & 13.7 & 100 & TAN \\
\hline TGx 1891-3F & 10.3 & 100 & 11.4 & 100 & TAN \\
\hline TGx 1895-49F & 8.9 & 100 & 15.1 & 100 & TAN \\
\hline TGx 1864-17F & 15.0 & 100 & 14.9 & 100 & TAN \\
\hline TGx 1440-1E & 53.5 & 100 & 52.2 & 100 & TAN \\
\hline TGx 1485-1D & 66.7 & 100 & 64.1 & 100 & TAN \\
\hline Samsoy-2 & 65.3 & 100 & 53.3 & 100 & TAN \\
\hline $\operatorname{LSD}(\alpha=0.05)$ & 4.9 & 6.0 & 2.2 & 3.5 & $\ldots$ \\
\hline
\end{tabular}

${ }^{x}$ Soybean breeding lines TGx 1485-1D and TGx 1440-1E are susceptible and Samsoy-2 is a local check.

${ }^{\mathrm{y}}$ Disease severity (DS) is based on diseased leaf area and sporulation is based on a sample size of 50 lesions.

${ }^{\mathrm{z}} \mathrm{RB}=$ reddish brown hypersensitive lesions with 0 to 6 pustules per lesion, and TAN $=$ tan-colored lesions with 1 to 14 pustules per lesion.

Table 5. Effect of the number of test line rows surrounded by an infector row on the uniformity of disease severity on test plants in field evaluation of soybean genotypes for resistance to soybean rust caused by Phakopsora pachyrhizi

\begin{tabular}{|c|c|c|c|c|c|}
\hline \multirow[b]{3}{*}{ Year, test rows } & \multicolumn{5}{|c|}{ Disease severity (\% diseased leaf area) ${ }^{\mathrm{z}}$} \\
\hline & \multicolumn{4}{|c|}{ Infector row surrounding no. of test line rows } & \multirow[b]{2}{*}{7 test line rows without infector row } \\
\hline & 1 row & 3 rows & 5 rows & 7 rows & \\
\hline \multicolumn{6}{|l|}{2004} \\
\hline 1 & 15.5 & $10.8 \mathrm{a}$ & $10.7 \mathrm{a}$ & $9.6 \mathrm{~b}$ & $3.4 \mathrm{ab}$ \\
\hline 2 & $\ldots$ & $9.9 \mathrm{a}$ & $5.4 \mathrm{~b}$ & $7.8 \mathrm{~b}$ & $2.7 \mathrm{ab}$ \\
\hline 3 & $\ldots$ & $11.5 \mathrm{a}$ & $2.4 \mathrm{c}$ & $5.2 \mathrm{c}$ & $2.7 \mathrm{ab}$ \\
\hline 4 & $\ldots$ & $\ldots$ & $5.3 \mathrm{~b}$ & $1.5 \mathrm{~d}$ & $1.5 \mathrm{~b}$ \\
\hline 5 & $\ldots$ & $\ldots$ & $10.4 \mathrm{a}$ & $5.2 \mathrm{c}$ & $3.5 \mathrm{ab}$ \\
\hline 6 & $\ldots$ & $\ldots$ & $\ldots$ & $8.0 \mathrm{~b}$ & $2.5 \mathrm{ab}$ \\
\hline 7 & $\ldots$ & $\ldots$ & $\ldots$ & $12.7 \mathrm{a}$ & $3.6 \mathrm{a}$ \\
\hline Mean & $\ldots$ & 10.7 & 6.8 & 7.1 & 2.8 \\
\hline \multicolumn{6}{|l|}{2005} \\
\hline 1 & 27.2 & $26.3 \mathrm{a}$ & $29.1 \mathrm{~b}$ & $31.6 \mathrm{~b}$ & $22.5 b$ \\
\hline 2 & $\ldots$ & $25.9 \mathrm{a}$ & $23.4 \mathrm{~d}$ & $26.8 \mathrm{c}$ & $19.2 \mathrm{de}$ \\
\hline 3 & $\ldots$ & $26.5 \mathrm{a}$ & $19.0 \mathrm{e}$ & $23.3 \mathrm{~d}$ & $18.0 \mathrm{e}$ \\
\hline 4 & $\ldots$ & $\ldots$ & $25.1 \mathrm{c}$ & $18.4 \mathrm{e}$ & $15.9 \mathrm{f}$ \\
\hline 5 & $\ldots$ & $\ldots$ & $31.6 \mathrm{a}$ & $20.3 \mathrm{e}$ & $20.6 \mathrm{~cd}$ \\
\hline 6 & $\ldots$ & $\ldots$ & $\ldots$ & $27.5 \mathrm{c}$ & $21.4 \mathrm{bc}$ \\
\hline 7 & $\ldots$ & $\ldots$ & $\ldots$ & $34.1 \mathrm{a}$ & $24.9 \mathrm{a}$ \\
\hline Mean & $\ldots$ & 26.2 & 25.6 & 26.0 & 20.3 \\
\hline
\end{tabular}

${ }^{\mathrm{z}}$ Within each column, mean values followed by similar letters are not significantly different based on the least significant difference $($ LSD) test at $=0.05$. The LSD $(\alpha=0.05)$ values to compare means across test line rows are 3.5 and 5.0 for 2004 and 2005, respectively. 
prevention of chlorophyll degradation and senescence of leaf pieces before the duration required to express symptom stages and disease severity levels necessary to differentiate between cultivar responses (32). Agar medium amended with kinetin at $10 \mathrm{mg} /$ liter was able to prevent chlorophyll degradation in soybean leaves for more than 18 days after plating. In this study, kinetin (a cytokinin) was a better hormone for retarding chlorosis of leaves than gibberellic acid, which was used earlier by Burdon and Marshall (9) to evaluate native Glycine spp. for rust resistance. Hormones vary in their ability to retard senescence of detached leaves in different plant species. For example, benzimidazole has been used in the incubation medium to study sugarcane rust system (2), gibberellic acid for banana sigatoka system (30), and cytokinin for wheat Fusarium blight (8) and rust systems (3). A concentration of $1 \times 10^{6}$ spores $/ \mathrm{ml}$ resulted in the highest number of pustules and spores per pustule but also higher levels of leaf necrosis. Therefore, we adopted a concentration of 1 $\times 10^{5}$ spores $/ \mathrm{ml}$ for subsequent inoculations when we evaluated genotypes for rust resistance using detached leaves and in the greenhouse. Our results also indicated that 3- to 4-week-old leaves should be used for optimal results in the detached-leaf assay.

The detached-leaf assay has several advantages. Each cycle of evaluation can be rapidly completed in about 40 days (21 days for plant growth and 18 days for disease evaluation). Further, various infection parameters can be evaluated easily at regular intervals on the same leaf to determine the rate of pathogen development and components of resistance in a large number of soybean lines, such as mapping populations. Being an obligate parasite, the rust pathogen is not easy to handle with respect to pathogen isolation, purification, maintenance, multiplication, and determining pathogenic potential. All these pathogen-handling steps can be carried out on detached leaves. Additionally, this assay is a useful tool for studying pathogenic variability that requires pure cultures of the rust pathogen, avoidance of cross contamination between cultures, inoculation of large number of rust isolates on several host differentials, and accurate quantification of pathogen development and reproduction. Certain precautions are required while conducting detached-leaf assays. Leaves should be free from mites, because they forage on rust spores which, in turn, reduce efficiency of infection. Surface sterilization of leaves with $0.1 \% \mathrm{NaOCl}$ or $70 \%$ ethanol also should be avoided because it causes patches of necrosis that interfere with pathogen development (data not shown).

Most of the PI- and GC- accessions exhibited high levels of rust resistance when evaluated using the detached-leaf assay and under greenhouse and field conditions. The accession PI 594538A exhibited almost complete resistance to soybean rust and PI 417089A and UG-5 were highly resistant. Among the genotypes evaluated in this study, PI 594538A, PI 417089A, and PI 462312 were reported previously as resistant to rust (22). Accession PI 462312 has a single gene $\left(R p p_{3}\right)$ for resistance (6), which has been overcome by some $P$. pachyrhizi isolates (33). In Uganda, lines GC 00138-29 and UG-5 were reported to have moderate and high levels of rust resistance, respectively (19). Crosses between PI 594538A, PI 417089A, and UG-5 and the susceptible breeding line TGx 1485-1D have generated several progenies with high levels of rust resistance (data not shown). The latter observation suggests that the resistance of PI 594538A, PI 417089A, and UG-5 is heritable and these genotypes can be valuable for the development of rust resistance in soybean. Although previous evaluations of PI 594538A reported TAN reaction lesion type (22), we observed no visible reaction on this accession during our evaluations following inoculation. This difference may be attributed to the rust isolates that were used for inoculation; whereas Miles et al. (22) used a mixture of four isolates from Thailand, Brazil, Paraguay, and Zimbabwe, the isolates used in the present study originated from Nigeria.

Several breeding lines did not exhibit resistance comparable with the other soybean accessions that were evaluated in this study. It is possible that high disease pressure under our experimental conditions could have masked the low to moderate levels of horizontal resistance in these lines. However, two breeding lines, TGx 1835-10E and TGx 1895-49F, had levels of disease severity, days to lesion appearance, and pustules per lesion comparable with those of PI 462312. Specifically, TGx 1835-10E had low disease severity compared with GC 00138-29, PI 368039 and PI 462312 when evaluated under field conditions. In addition, disease severity observed on TGx 1835-10E was not different from that of GC 00138-29 in greenhouse evaluations. TGx 1835-10E has been released as a rust-resistant cultivar named MAKSOY $1 \mathrm{~N}$ for general cultivation in Uganda (P. Tukamuhabwa, personal communication).

Strong correlations were observed between greenhouse and field disease data, except for days to pustule formation in the greenhouse and disease severity in the field. However, the former variable was strongly correlated with field sporulation. Particularly, disease severity data from field and greenhouse conditions were highly correlated. Based on our results, greenhouse screening can be especially useful when field screening is ineffective due to unsuitable environmental conditions or the simultaneous presence of other necrotic diseases that make rust evaluations difficult. However, successful greenhouse screening requires proper ambient conditions, such as temperature and relative humidity, and only a limited number of genotypes can be evaluated in a single run. Similar observations were reported by Foolad et al. (11) when investigating the

Table 7. Pearson correlation coefficients from disease data from 14 soybean genotypes to compare the similarities of detached-leaf assay, greenhouse, and field techniques in screening for rust resistance ${ }^{z}$

\begin{tabular}{|c|c|c|c|c|c|c|c|c|c|c|c|c|c|c|}
\hline & \multicolumn{2}{|c|}{ Field (Fld) } & \multicolumn{7}{|c|}{ Greenhouse (GH) } & \multicolumn{5}{|c|}{ Detached-leaf (DL) } \\
\hline & DS $(\%)$ & Spor $(\%)$ & LA & PF & PE & $\mathbf{L N}$ & PL & SP & DS (\%) & LA & $\mathbf{P F}$ & PE & $\mathbf{L N}$ & PL \\
\hline Fld-Spor & $0.60^{*}$ & & $\ldots$ & $\ldots$ & $\ldots$ & $\ldots$ & $\cdots$ & $\ldots$ & $\ldots$ & $\ldots$ & $\ldots$ & $\ldots$ & $\cdots$ & $\ldots$ \\
\hline GH-LA & $-0.57 *$ & $-0.81 * *$ & $\ldots$ & $\ldots$ & $\ldots$ & $\ldots$ & $\ldots$ & $\ldots$ & $\ldots$ & $\ldots$ & $\ldots$ & $\ldots$ & $\ldots$ & $\ldots$ \\
\hline GH-PF & $-0.58^{*}$ & $-0.92 * *$ & $0.73 * *$ & $\ldots$ & $\ldots$ & $\ldots$ & $\ldots$ & $\ldots$ & $\ldots$ & $\ldots$ & $\ldots$ & $\ldots$ & $\ldots$ & $\ldots$ \\
\hline GH-PE & $-0.58 *$ & $-0.92 * *$ & $0.73 * *$ & $0.99 * *$ & $\ldots$ & $\ldots$ & $\ldots$ & $\ldots$ & $\ldots$ & $\ldots$ & $\ldots$ & $\ldots$ & $\ldots$ & $\ldots$ \\
\hline GH-LN & $0.66^{*}$ & $0.89^{* *}$ & $-0.83 * *$ & $-0.95^{* *}$ & $-0.95^{* *}$ & $\ldots$ & $\ldots$ & $\ldots$ & $\ldots$ & $\ldots$ & $\ldots$ & $\ldots$ & $\ldots$ & $\ldots$ \\
\hline GH-PL & $0.78^{* *}$ & $0.88 * *$ & $-0.74 * *$ & $-0.88^{* *}$ & $-0.89 * *$ & $0.85 * *$ & 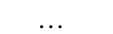 & $\ldots$ & $\ldots$ & $\ldots$ & $\ldots$ & $\ldots$ & $\ldots$ & $\ldots$ \\
\hline GH-SP & $0.88 * *$ & $0.84 * *$ & $-0.69 * *$ & $-0.86^{* *}$ & $-0.86^{* *}$ & $0.86^{* *}$ & $0.95 * *$ & $\ldots$ & $\ldots$ & $\ldots$ & $\ldots$ & $\ldots$ & $\ldots$ & $\ldots$ \\
\hline GH-LAI & $0.99 * *$ & $0.64^{*}$ & $-0.61 *$ & $-0.65 *$ & $-0.66^{*}$ & $0.73 * *$ & $0.81 * *$ & $0.92 * *$ & . & $\ldots$ & $\ldots$ & $\ldots$ & $\ldots$ & $\ldots$ \\
\hline DL-LA & $-0.55^{*}$ & $-0.76^{* *}$ & $0.86^{* *}$ & $0.65^{*}$ & $0.64^{*}$ & $-0.77 * *$ & -0.70 ** & $-0.64 *$ & $-0.57^{*}$ & . & $\ldots$ & $\ldots$ & $\ldots$ & $\ldots$ \\
\hline DL-PF & $-0.66^{*}$ & $-0.92 * *$ & $0.72 * *$ & $0.98 * *$ & $0.98 * *$ & $-0.92 * *$ & $-0.94 * *$ & $-0.91 * *$ & $-0.72 * *$ & $0.68 *$ & $\ldots$ & $\ldots$ & $\ldots$ & $\ldots$ \\
\hline DL-PE & $-0.66^{*}$ & $-0.83^{* *}$ & $0.75^{* *}$ & $0.88 * *$ & $0.89 * *$ & $-0.87 * *$ & $-0.91 * *$ & $-0.88 * *$ & $-0.72 * *$ & $0.67 *$ & $0.92 * *$ & & $\cdots$ & $\ldots$ \\
\hline DL-LN & $0.77 * *$ & $0.79 * *$ & $-0.75^{* *}$ & $-0.79 * *$ & $-0.79 * *$ & $0.86 * *$ & $0.82 * *$ & $0.86^{* *}$ & $0.80 * *$ & $-0.78 * *$ & -0.80 ** & $-0.78 * *$ & & $\ldots$ \\
\hline DL-PL & $0.74 * *$ & $0.91 * *$ & $-0.74 * *$ & $-0.92 * *$ & $-0.93 * *$ & $0.88 * *$ & $0.99 * *$ & $0.94 * *$ & $0.79 * *$ & $-0.67 * *$ & $-0.95 * *$ & $-0.91 * *$ & $0.85 * *$ & \\
\hline DL-SP & $0.89 * *$ & $0.83^{* *}$ & $-0.68 * *$ & $-0.84 * *$ & $-0.84 * *$ & $0.85^{* *}$ & $0.95 * *$ & $0.99 * *$ & $0.93 * *$ & $-0.62^{*}$ & $-0.89 * *$ & $-0.86^{* *}$ & $0.86 * *$ & $0.95 * *$ \\
\hline
\end{tabular}

${ }^{\mathrm{z}}$ DS $=$ disease severity (diseased leaf area), Spor $=$ sporulation, $\mathrm{LA}=$ days to lesion appearance, $\mathrm{PF}=$ days to pustule formation, $\mathrm{PE}=$ days to pustule eruption, $\mathrm{LN}=$ lesion number $/ \mathrm{cm}^{2}, \mathrm{PL}=$ pustules per lesion, and $\mathrm{SP}=$ spores per pustule, and $*$ and $* *=$ significant at $P<0.05$ and 0.01 , respectively. 
utility of detached leaves for screening tomato germplasm for early blight resistance. Nonetheless, where field screening is employed, optimal results will be obtained when an infector row is planted after every three rows of test genotypes. Such an approach of using infector rows in field screening to enhance high levels of uniform disease pressure has been employed in sorghum and peanut pathosystems $(23,28)$.

Results from the detached-leaf assay were very similar to those from the field and greenhouse evaluations, as judged by the significant correlations between field, greenhouse, and detached-leaf assay data. In particular, strong correlations were observed between disease severity and sporulation in the field and lesion number, pustules per lesion, and spores per pustule in the detached-leaf assay. Unlike field data, strong correlations were observed between all the disease components when genotypes were evaluated in the greenhouse and using the detached-leaf assay. Such high correlations between data from the detached-leaf assay, greenhouse, and field evaluations indicate that soybean rust screening can be carried out effectively and reliably using detached leaves. Furthermore, because the detached-leaf assay allows for simultaneous screening of soybean genotypes against multiple pathogen types, this can significantly speed up the breeding process by allowing multiple cycles of screening and selection in a given year at minimal cost. Based on these results and the potential implications for high-throughput screening, we conclude that detached-leaf assay is a useful procedure for screening soybean for rust resistance. The detached-leaf assay currently is being employed to study genetic diversity of $P$. pachyrhizi in Nigeria and to phenotype mapping populations for rust reaction.

\section{LITERATURE CITED}

1. Akinsanmi, O. A., Ladipo, J. L., and Oyekan, P. O. 2001. First report of soybean rust (Phakopsora pachyrhizi) in Nigeria. Plant Dis. 85:97.

2. Asnaghi, C., D'Hont, A., Glaszmann, J. C., and Rott, P. 2001. Resistance of sugarcane cultivar R 570 to Puccinia melanocephala isolates from different geographic locations. Plant Dis. 85:282-286.

3. Atif, A. H., and Wilcoxson, R. D. 1975. Responses of detached tissues of adult wheat plants to Puccinia graminis tritici. Phytopathology 65:318-321.

4. Bandyopadhyay, R., Paul, C., Twizeyimana, M., Adeleke, R., Miles, M. R., and Hartman,
G. L. 2006. Identification and development of resistance to soybean rust in Nigeria. (Abstr.) Phytopathology 96:S8.

5. Bonde, M. R., Nester, S. E., Austin, C. N., Stone, C. L., Frederick, R. D., Hartman, G. L., and Miles, M. R. 2006. Evaluation of virulence of Phakopsora pachyrhizi and P. meibomiae isolates. Plant Dis. 90:708-716.

6. Bromfield, K. R. 1984. Soybean Rust. Monogr. No. 11. American Phytopathological Society, St. Paul, MN.

7. Bromfield, K. R., and Hartwig, E. E. 1980. Resistance to soybean rust and mode of inheritance. Crop Sci. 20:254-255.

8. Browne, R. A., Murphy, J. P., Cooke, B. M., Devaney, D., Walsh, E. J., Griffey, C. A., Hancock, J. A., Harrison, S. A., Hart, P., Kolb, F. L., McKendry, A. L., Milus, E. A., Sneller, C., and Van Sanford, D. A. 2005. Evaluation of components of Fusarium head blight resistance in soft red winter wheat germ plasm using a detached leaf assay. Plant Dis. 89:404-411.

9. Burdon, J. J., and Marshall, D. R. 1981. Evaluation of Australian native species of Glycine for resistance to soybean rust. Plant Dis. 65:44-45.

10. Caldwell, P. M., and McLaren, N. W. 2004. Soybean rust research in South Africa. Pages 354-360 in: Proc. VII World Soybean Res. Conf. IV Int. Soybean Processing and Utilization Conference, III Brazilian Soybean Congress, Foz do Iguassu, PR, Brazil.

11. Foolad, M. R., Ntahimpera, N., Christ, J. B., and Yin, G. Y. 2000. Comparison of field, greenhouse, and detached-leaflet evaluation of tomato germ plasm for early blight resistance. Plant Dis. 84:967-972.

12. Gomez, K. A., and Gomez, A. A. 1984. Statistical Procedures for Agricultural Research, 2nd ed. John Wiley \& Sons, New York

13. Hartman, G. L. 1996. Highlights of soybean rust research at the Asian Vegetable Research and Development Center. Soybean Rust Workshop, 9-11 August 1995. J. B. Sinclair and G. L. Hartman, eds. College of Agriculture, Consumer, and Environmental Sciences, National Soybean Research Laboratory Publ. No.1, Urbana, IL.

14. Hartman, G. L., Miles, M. R., and Frederick, R. D. 2005. Breeding for resistance to soybean rust. Plant Dis. 89:664-666.

15. Hartman, G. L., Wang, T. C., and Hymowitz, T. 1992. Sources of resistance to soybean rust in perennial Glycine species. Plant Dis. 76:396-399.

16. Hartman, G. L., Wang, T. C., and Tschanz, A. T. 1991. Soybean rust development and the quantitative relationship between rust severity and soybean yield. Plant Dis. 75:596-600.

17. Ivancovich, A. 2005. Soybean rust in Argentina. Plant Dis. 89:667-668.

18. Kawuki, R. S., Adipala, E., Lamo, J., and Tukamuhabwa, P. 2003. Responding to the soybean rust epidemic in sub-Saharan Africa: a review. Afr. Crop. Sci. J. 11:301-318.

19. Kawuki, R. S., Adipala, E., and Tukamuhabwa, P. 2003. Yield loss associated with soybean rust (Phakopsora pachyrhizi Syd.) in Uganda. J. Phytopathol. 151:7-12.

20. Kawuki, R. S., Tukamuhabwa, P., and Adipala,
E. 2006. Soybean rust severity, rate of rust development, and tolerance as influenced by maturity period and season. Crop Prot. 23:447455.

21. Miles, M. R., Frederick, R. D., and Hartman, G. L. 2003. Soybean rust: is the U.S. crop at risk? APSnet Feature, American Phytopathological Society. Online publication.

22. Miles, M. R., Frederick, R. D., and Hartman, G. L. 2006. Evaluation of soybean germplasm for resistance to Phakopsora pachyrhizi. Online. Plant Health Progress doi:10.1094/ PHP-2006-0104-01-RS.

23. Pande, S., Thakur, R. P., Karunakar, R. I., Bandyopadhyay, R., and Reddy, B. V. S. 1994. Development of screening methods and identification of stable resistance to anthracnose in sorghum. Field Crops Res. 38:157-166.

24. Roux, S. R., Hackauf, B., Linz, A., Ruge, B., Klocke, B., and Wehling, P. 2004. Leaf-rust resistance in rye (Secale cereale L.). 2. Genetic analysis and mapping of resistance genes $\operatorname{Pr} 3$ Pr4, and Pr5. Theor. Appl. Genet. 110:192201.

25. Schneider, R. W., Hollier, C. A., Whitam, H. K., Palm, M. E., McKenny, J. M., Hernandez, J. R., Levy, L., and Devries-Paterson, R. 2005. First report of soybean rust caused by Phakopsora pachyrhizi in the continental United States. Plant Dis. 89:774.

26. Singh, B. B. 2006. Success of soybean in India: the early challenges and pioneer promoters. Asian Agri-History 10:41-47.

27. Singh, B. B., Gupta, S. C., and Singh, B. D. 1974. Sources of field resistance to rust (Pha kopsora pachyrhizi) and yellow mosaic diseases of soybean. Indian J. Genet. Plant Breed. $34: 400-404$

28. Subrahmanyam, P., Naidu, R. A., Reddy, L. J., Lava Kumar, P., and Ferguson, M. E. 2001. Resistance to groundnut rosette disease in wild Arachis species. Ann. Appl. Biol. 139:45-50.

29. Toledo, J. F. F. 2006. Breeding for rust resistance in Brazil. Paper presented at the Nationa Soybean Rust Symposium, St. Louis, MO. Plant Management Network. Published online.

30. Twizeyimana, M., Ojiambo, P. S., Tenkouano, A., Ikotun, T., and Bandyopadhyay, R. 2007. Rapid screening of Musa species for resistance to black leaf streak using in vitro plantlets in tubes and detached leaves. Plant Dis. 91:308 314.

31. Wehling, P., Linz, A., Hackauf, B., Roux, S. R., Ruge, B., and Klocke, B. 2003. Leaf-rust resistance in rye (Secale cereale L.). 2. Genetic analysis and mapping of resistance genes $\operatorname{Prl}$ and $\operatorname{Pr} 2$. Theor. Appl. Genet. 107:432-438.

32. Xie, G. L., and Mew, T. W. 1998. A leaf inoculation method for detection of Xanthomonas oryzae pv. oryzicola from rice seed. Plant Dis. 82:1007-1011.

33. Yeh, C. C. 1983. Physiological races of $P h a$ kopsora pachyrhizi in Taiwan. J. Agric. Res. (Taiwan) 32:69-74.

34. Yorinori, J. T., Pavia, W. M., Frederick, R. D., Costamilan, L. M., Bertagnolli, P. F., Hartman, G. L., Godoy, C., and Nunes, J., Jr. 2005. Epidemics of soybean rust (Phakopsora pachyr hizi) in Brazil and Paraguay from 2001 to 2003. Plant Dis. 89:675-677. 